\title{
The Correctional and Social Component of the Additional Education of Orphans and Children with Disabilities on the Example of the Program "We Can do Everything Ourselves"
}

\author{
Ekaterina Scherbakova ${ }^{1, a *}$ \\ 1 NO Fond Podelis Teplom, 121059, 20/40 Berezhkovskaya Naberezhnaya str., \\ Moscow, Russia \\ aekaterina.sherbakova@yandex.ru \\ ${ }^{*}$ Corresponding author
}

Keywords: orphans, disabilities, socialization, children, Russia

\begin{abstract}
The article deals with the problems of socialization of orphans and children with disabilities. By the example of additional education programs (football sections), the results of monitoring the sponsored educational institutions, characterizing the impact of the football section's activities on the physical and sociopsychological level of development of students and pupils.
\end{abstract}

\section{Introduction}

The profound sociocultural changes currently taking place in Russia determine the relevance of introducing educational programs and technologies focused on the qualitative improvement of the process of socialization [9] of orphans [5] and children with disabilities [7]. Such programs should provide opportunities for developing and restoring abilities, correcting and compensating impaired body functions, preparing children for independent living, vocational guidance.

At the same time, social and pedagogical work conducted in orphanages, boarding schools, ans correctional-type schools is characterized by low efficiency. The overwhelming majority of students [8] have a non-standard socio-psychological development; there are pronounced communicative problems in the behavioral sphere [2]. The absence of (a) foreign language and computer technology classes in programs of correctional schools and orphanages and (b) sports sections deprives students of equal educational opportunities [3]. Orphans and children with disabilities [1], as a rule, have a limited outlook due to their particular upbringing and low cognitive needs of such children.

All this requires an additional introduction to the educational process of students developing activities [4] aimed at the development of mental reserves, ensuring a sufficient level of personality development, orientation in the outside world, and the formation of applied skills.

Additional education is intended to increase the space in which students can develop creative and cognitive activity, realize the best personal qualities, demonstrate those abilities that often remain unclaimed in basic education. Social and correctional orientation of additional education [6] has a wide range of tasks and means of their implementation, the solution of which is aimed at the content of the project "We can do it ourselves."

\section{Methods}

The goal of monitoring is to improve the effectiveness and quality of football classes, performance appraisal. Monitoring allows to get data, characterizing the impact of football classes on the physical and sociopsychological level of children development.

Partner educational institutions in which the monitoring took place in 2017 are:

- The Center of Special Education No. 3;

- The Schuiskiy orphans boarding school;

- The Rybnovskaya boarding school for orphans and children without parental care; 
- The Voronezh boarding school No 1.

In order to define the effectiveness of process, the following criteria was set:

- Technical training indicators;

- Physical training indicators;

- Level of motivation development;

- Level of self-appraisal;

- Level of educational institution performance satisfaction among children.

Taking into account the tasks, the following methods were chosen to conduct monitoring:

- Technical training indicators measurement;

- Physical training indicators measurement;

- Diagnostics of achievement motivation (Potemkina, O.F., Potemkina, E.V.);

- Self-appraisal examination (questionnaire by Kazantseva, G.N.);

- Methods of school life satisfaction examination (Andreeva, A.L.).

In every group of football class teachers (teacher-psychologist, trainer) were carried our diagnostics, taking into account individual peculiarities of children.

\section{Research}

Diagnostic results of the Center of Special education No 3.

15 people took part in diagnostics in March 2017.

Technical training indicators.

\begin{tabular}{|c|l|l|c|}
\hline № & \multicolumn{1}{|c|}{ Task } & \multicolumn{1}{|c|}{ Conditions } & Average result \\
\hline 1 & Running with dribbling (20 m) & The best result was taken out of 3 tries & 10,4 sec \\
\hline 2 & $\begin{array}{l}\text { Dribbling, dribbling with } \\
\text { stands, shots }\end{array}$ & Sum of goals out of 3 tries & 0,5 times \\
\hline 3 & Shot to set a part of woodwork & $\begin{array}{l}\text { Shot from 12 meters to the part of woodwork set by a } \\
\text { trainer (3 parts given), the sum of goals. }\end{array}$ & 0,6 times \\
\hline 4 & Precision of goals & $\begin{array}{l}\text { Shot from 12 meters with a static ball, 3 tries, the sum of } \\
\text { goals; from a distance of 12 meters, a fixed ball was hit } \\
\text { into the goal, 3 attempts were made, the amount of hits } \\
\text { was taken into account. }\end{array}$ & 1,6 times \\
\hline 5 & Juggling & Max quantity of kicks done with different methods & 5,5 times \\
\hline
\end{tabular}

Physical training indicators.

\begin{tabular}{|c|l|l|c|}
\hline № & \multicolumn{1}{|c|}{ Task } & \multicolumn{1}{|c|}{ Conditions } & Average result \\
\hline 1 & Push-ups & Max results & 15,2 times \\
\hline 2 & $\begin{array}{l}\text { A standing long } \\
\text { jump }\end{array}$ & But result of 3 tries & $215 \mathrm{sm}$ \\
\hline 3 & Curl-up, 30 sec & Max quantity of curl-ups done in 30 sec & 23,5 times \\
\hline 4 & Flexibility & $\begin{array}{l}\text { 2 bends, standing on the edge of a bench, doing max bend on the 3rd } \\
\text { try and staying for 2-3 sec, do not bend knees }\end{array}$ & $-2,2 \mathrm{~cm}$ \\
\hline 5 & Shuttle run, 3x10 & 1 try & $7,1 \mathrm{~s}$ \\
\hline
\end{tabular}


Level of self-appraisal.

\begin{tabular}{|l|c|c|}
\hline Level of self-appraisal & Number of picks & $\mathbf{\%}$ \\
\hline Medium & 7 & 47 \\
\hline High & 8 & 53 \\
\hline
\end{tabular}

School life satisfaction examination.

\begin{tabular}{|l|c|c|}
\hline \multicolumn{1}{|c|}{ Level of satisfaction } & Number of picks & $\mathbf{\%}$ \\
\hline Low & 2 & 13 \\
\hline Medium & 9 & 60 \\
\hline High & 4 & 27 \\
\hline
\end{tabular}

Diagnostics of achievement motivation.

\begin{tabular}{|l|c|c|}
\hline Dominance motivation & Number of picks & $\mathbf{\%}$ \\
\hline Success achievement & 4 & 27 \\
\hline Escaping failure & 8 & 53 \\
\hline Not defined & 3 & 20 \\
\hline
\end{tabular}

Results of diagnostics in the Schuiskiy Orphans Boarding School.

33 people took part in diagnostics in March 2017

Technical training indicators.

\begin{tabular}{|c|l|l|c|}
\hline № & \multicolumn{1}{|c|}{ Task } & \multicolumn{1}{c|}{ Conditions } & Average result \\
\hline 1 & Running with dribbling (20 m) & The best result was taken out of 3 tries & 11,9 sec \\
\hline 2 & $\begin{array}{l}\text { Dribbling, dribbling with } \\
\text { stands, shots }\end{array}$ & Sum of goals out of 3 tries & 1,8 times \\
\hline 3 & Shot to set a part of woodwork & $\begin{array}{l}\text { Shot from 12 meters to the part of woodwork set by a } \\
\text { trainer (3 parts given), the sum of goals. }\end{array}$ & 1,4 times \\
\hline 4 & Precision of goals & $\begin{array}{l}\text { Shot from 12 meters with a static ball, 3 tries, the sum of } \\
\text { goals; from a distance of 12 meters, a fixed ball was hit } \\
\text { into the goal, 3 attempts were made, the amount of hits } \\
\text { was taken into account. }\end{array}$ & 1,9 time \\
\hline 5 & Juggling & Max quantity of kicks done with different methods & 10,5 times \\
\hline
\end{tabular}

Physical training indicators.

\begin{tabular}{|c|l|l|c|}
\hline \multicolumn{1}{|c|}{ Task } & \multicolumn{1}{c|}{ Conditions } & Average result \\
\hline 1 & Push-ups & Max results & 23,5 times \\
\hline 2 & A standing long jump & But result of 3 tries & $176,2 \mathrm{~cm}$ \\
\hline 3 & Curl-up, 30 sec & Max quantity of curl-ups done in 30 sec & 20 times \\
\hline 4 & Flexibility & $\begin{array}{l}\text { 2 bends, standing on the edge of a bench, doing max } \\
\text { bend on the 3rd try and staying for 2-3 sec, do not bend } \\
\text { knees }\end{array}$ & $4 \mathrm{~cm}$ \\
\hline 5 & Shuttle run, 3x10 & 1 try & $9,1 \mathrm{~s}$ \\
\hline
\end{tabular}

Level of self-appraisal.

\begin{tabular}{|l|l|c|}
\hline Level of self-appraisal & Number of picks & $\mathbf{\%}$ \\
\hline Low & 1 & $3 \%$ \\
\hline Medium & 19 & $58 \%$ \\
\hline High & 13 & $39 \%$ \\
\hline
\end{tabular}

School life satisfaction examination.

\begin{tabular}{|l|l|c|}
\hline \multicolumn{1}{|c|}{ Levels of satisfaction } & Number of picks & $\mathbf{\%}$ \\
\hline Low & 2 & $6 \%$ \\
\hline Medium & 17 & $52 \%$ \\
\hline High & 14 & $42 \%$ \\
\hline
\end{tabular}


Diagnostics of achievement motivation.

\begin{tabular}{|c|c|c|c|c|}
\hline Grade & Number of pupils & Success achievement & Escaping failure & Not defined \\
\hline 8 & 7 & 0 & 7 & 0 \\
\hline 9 & 9 & 0 & 9 & 0 \\
\hline & 16 & 0 & 16 & 0 \\
\hline
\end{tabular}

Results of diagnostics examination in the Voronezh Boarding School No. 1.

18 people took place in diagnostics in March 2017.

Technical training indicators.

\begin{tabular}{|c|l|l|c|}
\hline № & \multicolumn{1}{|c|}{ Task } & \multicolumn{1}{|c|}{ Conditions } & Average result \\
\hline 1 & $\begin{array}{l}\text { Running with dribbling (20 } \\
\text { m) }\end{array}$ & The best result was taken out of 3 tries & $5,4 \mathrm{sec}$ \\
\hline 2 & $\begin{array}{l}\text { Dribbling, dribbling with } \\
\text { stands, shots }\end{array}$ & Sum of goals out of 3 tries & 2,3 times \\
\hline 3 & $\begin{array}{l}\text { Shot to set a part of } \\
\text { woodwork }\end{array}$ & $\begin{array}{l}\text { Shot from 12 meters to the part of woodwork set by a } \\
\text { trainer (3 parts given), the sum of goals. }\end{array}$ & 2,5 times \\
\hline 4 & Precision of goals & $\begin{array}{l}\text { Shot from 12 meters with a static ball, 3 tries, the sum of } \\
\text { goals; from a distance of 12 meters, a fixed ball was hit } \\
\text { into the goal, 3 attempts were made, the amount of hits } \\
\text { was taken into account. }\end{array}$ & 2,3 times \\
\hline 5 & Juggling & Max quantity of kicks done with different methods & 28,1 times \\
\hline
\end{tabular}

Physical training indicators.

\begin{tabular}{|c|l|l|c|}
\hline \multicolumn{1}{|c|}{ Task } & \multicolumn{1}{|c|}{ Conditions } & Average result \\
\hline 1 & Push-ups & Max results & 26,6 times \\
\hline 2 & A standing long jump & But result of 3 tries & $185,8 \mathrm{~cm}$ \\
\hline 3 & Curl-up, 30 sec & Max quantity of curl-ups done in 30 sec & 32,4 times \\
\hline 4 & Flexibility & $\begin{array}{l}\text { 2 bends, standing on the edge of a bench, doing max bend } \\
\text { on the 3rd try and staying for 2-3 sec, do not bend knees }\end{array}$ & $+\mathrm{cm}$ \\
\hline 5 & Shuttle run, 3x10 & 1 try & $12,4 \mathrm{sec}$ \\
\hline
\end{tabular}

Level of self-appraisal.

\begin{tabular}{|l|c|c|}
\hline Level of self-appraisal & Number of picks & $\mathbf{\%}$ \\
\hline Low & 3 & $15 \%$ \\
\hline Medium & 9 & $50 \%$ \\
\hline High & 6 & $35 \%$ \\
\hline
\end{tabular}

School life satisfaction examination.

\begin{tabular}{|l|c|c|}
\hline Levels of satisfaction & Number of picks & $\mathbf{\%}$ \\
\hline Low & 3 & $15 \%$ \\
\hline Medium & 14 & $80 \%$ \\
\hline High & 1 & $5 \%$ \\
\hline
\end{tabular}

Diagnostics of achievement motivation.

\begin{tabular}{|l|c|c|}
\hline Dominance motivation & Number of picks & $\mathbf{\%}$ \\
\hline Success achievement & 11 & 61 \\
\hline Escaping failure & 7 & 39 \\
\hline
\end{tabular}

Results of diagnostics examination in the Rybnovskaya Boarding School for Orphans and Children without Parental Care. 30 people took part in diagnostics in March 2017.

Technical training indicators. 


\begin{tabular}{|c|l|l|c|}
\hline № & \multicolumn{1}{|c|}{ Task } & \multicolumn{1}{|c|}{ Conditions } & \multicolumn{1}{|c|}{ Average result } \\
\hline 1 & $\begin{array}{l}\text { Running with dribbling (20 } \\
\text { m) }\end{array}$ & The best result was taken out of 3 tries & 6,2 \\
\hline 2 & $\begin{array}{l}\text { Dribbling, dribbling with } \\
\text { stands, shots }\end{array}$ & Sum of goals out of 3 tries & 1,1 \\
\hline 3 & $\begin{array}{l}\text { Shot to set a part of } \\
\text { woodwork }\end{array}$ & $\begin{array}{l}\text { Shot from 12 meters to the part of woodwork set by a } \\
\text { trainer (3 parts given), the sum of goals. }\end{array}$ & 1 \\
\hline 4 & Precision of goals & $\begin{array}{l}\text { Shot from 12 meters with a static ball, 3 tries, the sum of } \\
\text { goals; from a distance of 12 meters, a fixed ball was hit } \\
\text { into the goal, 3 attempts were made, the amount of hits } \\
\text { was taken into account. }\end{array}$ & 1,3 \\
\hline 5 & Juggling & Max quantity of kicks done with different methods & 36,2 \\
\hline
\end{tabular}

Physical training indicators.

\begin{tabular}{|c|l|l|c|}
\hline № & \multicolumn{1}{|c|}{ Task } & \multicolumn{1}{c|}{ Conditions } & Average result \\
\hline 1 & Push-ups & Max results & 25,3 \\
\hline 2 & A standing long jump & But result of 3 tries & 173,1 \\
\hline 3 & Curl-up, 30 sec & Max quantity of curl-ups done in 30 sec & 32,4 \\
\hline 4 & Flexibility & $\begin{array}{l}\text { 2 bends, standing on the edge of a bench, doing max bend } \\
\text { on the 3rd try and staying for 2-3 sec, do not bend knees }\end{array}$ & 4,4 \\
\hline 5 & Shuttle run, 3x10 & 1 try & 11,8 \\
\hline
\end{tabular}

Level of self-appraisal.

\begin{tabular}{|l|c|c|}
\hline Level of self-appraisal & Number of picks & $\mathbf{\%}$ \\
\hline Medium & 15 & 50 \\
\hline High & 15 & 50 \\
\hline
\end{tabular}

School life satisfaction examination.

\begin{tabular}{|l|c|c|}
\hline \multicolumn{1}{|c|}{ Levels of satisfaction } & Number of picks & $\mathbf{\%}$ \\
\hline Low & 5 & 16 \\
\hline Medium & 10 & 33 \\
\hline High & 15 & 51 \\
\hline
\end{tabular}

Diagnostics of achievement motivation.

\begin{tabular}{|l|c|c|}
\hline Dominance motivation & Number of picks & $\mathbf{\%}$ \\
\hline Success achievement & 6 & 20 \\
\hline Escaping failure & 17 & 47 \\
\hline Not defined & 7 & 23 \\
\hline
\end{tabular}

Overall diagnostics results. 96 people took part in diagnostics in March 2017

Technical training indicators.

\begin{tabular}{|c|l|l|c|}
\hline № & \multicolumn{1}{|c|}{ Task } & \multicolumn{1}{|c|}{ Conditions } & $\begin{array}{c}\text { Average } \\
\text { result }\end{array}$ \\
\hline 1 & $\begin{array}{l}\text { Running with dribbling } \\
(20 \mathrm{~m})\end{array}$ & The best result was taken out of 3 tries & $8,5 \mathrm{sec}$ \\
\hline 2 & $\begin{array}{l}\text { Dribbling, dribbling } \\
\text { with stands, shots }\end{array}$ & Sum of goals out of 3 tries & 1,2 times \\
\hline 3 & $\begin{array}{l}\text { Shot to set a part of } \\
\text { woodwork }\end{array}$ & $\begin{array}{l}\text { Shot from 12 meters to the part of woodwork set by a trainer }(3 \\
\text { parts given), the sum of goals. }\end{array}$ & 1,4 times \\
\hline 4 & Precision of goals & $\begin{array}{l}\text { Shot from 12 meters with a static ball, 3 tries, the sum of goals; } \\
\text { from a distance of 12 meters, a fixed ball was hit into the goal, 3 } \\
\text { attempts were made, the amount of hits was taken into account. }\end{array}$ & 1,8 times \\
\hline 5 & Juggling & Max quantity of kicks done with different methods & 20,1 times \\
\hline
\end{tabular}


Physical training indicators.

\begin{tabular}{|c|l|l|c|}
\hline № & \multicolumn{1}{|c|}{ Task } & \multicolumn{1}{c|}{ Conditions } & $\begin{array}{c}\text { Average } \\
\text { result }\end{array}$ \\
\hline 1 & Push-ups & Max results & 22,7 times \\
\hline 2 & A standing long jump & But result of 3 tries & $187,5 \mathrm{~cm}$ \\
\hline 3 & Curl-up, 30 sec & Max quantity of curl-ups done in 30 sec & 27,1 times \\
\hline 4 & Flexibility & $\begin{array}{l}\text { 2 bends, standing on the edge of a bench, doing max bend on the } \\
\text { 3rd try and staying for 2-3 sec, do not bend knees }\end{array}$ & $2,1 \mathrm{~cm}$ \\
\hline 5 & Shuttle run, 3x10 & 1 try & $10,1 \mathrm{sec}$ \\
\hline
\end{tabular}

Level of self-appraisal.

\begin{tabular}{|l|c|c|}
\hline Level of self-appraisal & Number of picks & $\mathbf{\%}$ \\
\hline Low & 4 & 4 \\
\hline Medium & 50 & 52 \\
\hline High & 42 & 44 \\
\hline
\end{tabular}

The medium level of self-appraisal was find out in $52 \%$ of the pupils. That means that children feel confident in different situations and feel capable of dealing with different barriers; $44 \%$ of them have high level of self-appraisal, which means, that children doubt their performance very rarely and do not fix others remarks; $4 \%$ of them have low level of self-esteem, so pupils can be hurt by critics and try to match with others expectations.

School life satisfaction examination.

\begin{tabular}{|l|c|c|}
\hline \multicolumn{1}{|c|}{ Satisfaction levels } & Number of picks & $\mathbf{\%}$ \\
\hline Low & 12 & 13 \\
\hline Medium & 50 & 52 \\
\hline High & 34 & 35 \\
\hline
\end{tabular}

Diagnostics of achievement motivation.

\begin{tabular}{|l|c|c|}
\hline Dominance motivation & Number of picks & $\mathbf{\%}$ \\
\hline Success achievement & 21 & 24 \\
\hline Escaping failure & 48 & 56 \\
\hline Not defined & 17 & 20 \\
\hline
\end{tabular}

According to results, the majority of student are motivated by escaping failure.

\section{Conclusion}

The systemic and versatile additional impact on deviations (defects) in the development of orphans and children with disabilities, the creation of conditions for successful socialization and adaptation to modern living conditions allow solving correctional, developmental, and prophylactic tasks. Correctional tasks: to enrich the social situation in the development of children with the factors of successful mental, intellectual, social, emotional, and physical development; to provide correction and development of higher mental functions; to create conditions for the correction of educational, cognitive, speech, emotional-volitional, and personal spheres of the child to the standard age indicators; to ensure the correction and development of the motor sphere of children. Developmental tasks include: developing cognitive activity and independent mental activity of students; identifying the applied abilities of children, promoting their career guidance; ensuring the achievement of real creative results in a relatively short time; promoting the personal growth of children; ensuring the participation of orphans and children with disabilities (regardless of the severity of developmental disorders) in educational, recreational, sports, and other leisure activities. Preventive tasks include: improving health, the functionality of the body; ensuring the prevention of the influence of unfavorable social and psychological conditions of life, defects in education.

There were also an annual football tournament involving children from boarding schools and children with disabilities (mental retardation and children with diabetes). The main goal of the tournament was the 
socialization of orphans, socialization of children with special needs, adaptation in society, and provision of equal opportunities for children and gender equity. Such an event allows children to forget their differences, to share experiences and problems, to feel like just kids who came to play football, to socialize.

\section{References}

[1] Aabanina K.A., Rogoten N. N., \& Fedorov O. G. (2016). Modern problems, trends and ways of socialization of children with disabilities in school. Social Relations, 2, pp. 59-66.

[2] Alekhina, S.V. (2016). Inclusive education: from politics to practice. Psychological Science and Education, 21(1), pp. 136-145.

[3] Bakhtin, M. B., Dovbysh, S. E., Arinushkina, A. A., \& Molchanova, V.S. (2017). Modern approaches and monitoring of the quality of training of managers of educational organizations in the organization of inclusive education. Education Management: Theory and Practice, 3(27), pp. 234-239.

[4] Bakhtin, M. B., Dovbysh, S. E., Arinushkina, A. A., \& Molchanova, V.S. (2017). The practice of methodological counseling for specialists of schools of adoptive parents and family support services. Man and Education, 4, pp. 127-132.

[5] Bondarenko, A. V., \& Lukiyanov, M. Yu. (2015). Problems of socialization of orphans and children left without parental care in the post-internatal period (social and legal aspect). Eurasian Law Journal, 7, pp. 295-297.

[6] Kozlova, Yu. G. (2016). Correctional orientation of additional education. In Education: tradition and innovation (pp. 150-152). Moscow, Russia.

[7] Kuzmina, A. A. (2017). Socialization of children with disabilities. Almanac of World Science, 3(2), pp. $75-76$.

[8] Voitenko, T. P., \& Mironova, M. N. (1999). Problems of children's development in orphanages and boarding schools. Psychology Issues, 2, pp. 118-120.

[9] Vorontsova, M. V., et al. (2016). Adaptation and socialization of orphans and children left without parental care in conditions of a small orphanage. Moscow, Russia. 